Citation: F. Ferrari, S. lacuone, S. Scorrano, M. Fuschi (2020). The Role of Commerce in the Main Urban Area of Abruzzo: an Intra-Urban Reading. Bollettino della Società Geografica Italiana serie 14, 3 Special Issue: 93-103. doi: $10.36253 /$ bsgi-997

Copyright: ( 2020 F. Ferrari, S. lacuone, S. Scorrano, M. Fuschi. This is an open access, peer-reviewed article published by Firenze University Press (http://www.fupress.com/bsgi) and distributed under the terms of the Creative Commons Attribution License, which permits unrestricted use, distribution, and reproduction in any medium, provided the original author and source are credited.

Data Availability Statement: All relevant data are within the paper and its Supporting Information files.

Competing Interests: The Author(s) declare(s) no conflict of interest.

For Italian evaluation purposes: M. Fuschi is responsible for section 1, 2 and Conclusions, F. Ferrari for section 3, S. Scorrano for section $4, \mathrm{~S}$. lacuone for section 5 .

\section{The Role of Commerce in the Main Urban Area of Abruzzo: an Intra-Urban Reading}

\section{Il ruolo del commercio nella principale area urbana d'Abruzzo: una lettura a scala intra-urbana}

\author{
Fabrizio Ferrari ${ }^{1}$, Silvia Iacuone ${ }^{1}$, Silvia Scorrano ${ }^{2}$, Marina Fuschi $^{1}$ \\ ${ }^{1}$ Dipartimento di Economia (DEc), Università degli Studi “G. d’Annunzio" di Chieti- \\ Pescara, Pescara, Italy \\ ${ }^{2}$ Dipartimento di Lettere, Arti e Scienze Sociali (DiLASS), Università degli Studi "G. \\ d'Annunzio" di Chieti-Pescara, Italy \\ E-mail: fabrizio.ferrari@unich.it; silvia.iacuone@unich.it; silvia.scorrano@unich.it; \\ marina.fuschi@unich.it
}

\begin{abstract}
Since the 1950s, the urban structure of Abruzzo has gradually polarized on the area of Pescara-Chieti, as the expression of a series of location and settlement advantages. There, the trade sector, favoured by a period of expansion of large-scale commercial distribution, represented a powerful vehicle for territorial convergence and cohesion, contributing to the progressive process of marginalization of urban proximity trade. The aim of this work is to go beyond the opposition between suburban shopping center/central urban trade and to propose an interpretation at intra-urban scale that starts from peripheral neighbourhoods and peculiar spaces: They are able, in some cases, to better represent urban identity, but, above all, to provide a favourable observation point from which to promote a balanced and sustainable reorganization of the city.
\end{abstract}

Keywords: commerce, Pescara-Chieti area, urban neighborhoods, vulnerability, city project.

Riassunto. La struttura urbana abruzzese si è progressivamente polarizzata, a partire dagli anni Cinquanta, sull'area Pescara-Chieti, espressione di una serie di vantaggi localizzativi e insediativi. Qui, il comparto del commercio, grazie alla stagione della grande distribuzione commerciale, ha rappresentato un potente veicolo di convergenza e coesione territoriale, contribuendo al progressivo processo di marginalizzazione del commercio di prossimità cittadino. Obiettivo del presente lavoro è quello di andare oltre l'approccio contrappositivo centro commerciale suburbano/commercio centrale urbano per proporre una lettura a scala intra-urbana muovendo dai quartieri periferici e dagli spazi peculiari capaci, in alcuni casi, di raccontare meglio l'identità urbana, ma soprattutto di fornire un osservatorio privilegiato da cui partire per promuovere una riorganizzazione equilibrata e sostenibile della città.

Parole chiave: Commercio, area Pescara-Chieti, quartieri urbani, vulnerabilità, città progetto. 


\section{Introduction}

The urban structure of Abruzzo reflects the features of a diversified and dualistic territorial dynamic, witnessed by the presence of a single large urban area gravitating in the coastal and valley belt, more widely coalescent with the coastal town sprawl and with a system of "isle cities" (Fuschi 2006) spreading along the inner mountain areas (Landini 1976; Salvatori 1993). The "isle cities" are poorly integrated, weak in their socio-demographic and functional features as well as vulnerable in their geomorphological structure, which is characterized by seismicity (Landini, Massimi 2010).

The crucial point of this system is the urban area of Pescara-Chieti, centered on the two cities which are just 16 kilometers away. Their proximity has generated a conurbation (Massimi 1989) that is particularly evident in the valley area corresponding to the ribbon-like configuration of Chieti Scalo, perfectly welded with the western expansion of Pescara, while the hilly historical core Chieti Alta - keeps an isolated feature from the geomorphological ${ }^{1}$ and socio-cultural points of view.

The trade sector has been a powerful way to create territorial convergence and cohesion since the 1980's (Landini 1981), when the period of the growing of the large-scale retail sector (Bullado, Buzzetti 2001; Bottini 2005; Cirelli 2007; D'Alessandro 2015) fostered a further suburbanization driven by remarkable economic benefits, such as accessibility, scale and land advantages (that are typical of Fordist and capitalist systems). All these aspects contributed to the growth of the main urban area of Abruzzo, triggering, by means of substantial increases in size, rhythm and frequency of relationships, the urban strengthening and the rehabilitation of suburbs.

The analyzed area is, therefore, an urban agglomeration surrounded by shopping malls that operate as focal points around which new forms of territorial coagulation, following the phase of settlement dispersion, have emerged. According to the "new retail geography" (Wrigley, Lowe 1996), their role has gone beyond the mere retail activity and has reached a more intricated situation characterized by the change in lifestyle and in purchase habits of individuals, which foreshadows new spaces for recreational tertiary and signs a paradigmatic association between economic factors and cultural reasonings (Jackson 2002; Wrigley, Lowe 2002; Jackson, Thrift 1995; Wiedenhoft, Murphy 2017).

\footnotetext{
${ }^{1}$ It should be noted that the hilly slopes of Chieti, characterized by a marl-clayey structure, vulnerable to landslides, have heavily prevented the development of the edification and the connection between the upper and the lower parts of the city (Ferrari 2019).
}

The vitality and commercial density of the urban area of Pescara-Chieti (which was very important for the whole region and for adjacent subregions) also produced a progressive marginalization of urban proximity trade (Cirelli 2009, 2016), amplified by the economic crisis and the advent of e-commerce. Thus, in this way, Pescara and Chieti have taken on the features of the typical post-modern cities, transformed and partially emptied in their central commercial landscapes and weakened in their size and demographic composition.

The aim of this paper is to go beyond the opposition between suburban commercial area and central urban commercial $\mathrm{area}^{2}$, by analyzing the role of the commerce in the most peculiar and representative intra-urban areas and to contribute to a redefinition of the resilience of the contemporary city able to show the factors of vulnerability and to reveal the limits of urban planning. All these aspects are in full compliance with the most recent related scientific production, that has emphasized the plurality of the commercial landscapes - such as those of the main streets, the ethnic and the suburban ones - and has proposed a careful narrative of the dynamics that feed the different urban mosaic tiles (Carreras i Verdaguer, D’Alessandro 2017; D’Alessandro, Viganoni, 2013; Loda, Mancini 2003; Clerici, Faravelli 2006).

This paper specifically deals with peculiarities and vulnerabilities: in the first case study - the retail sector in Chieti Scalo - we analyze the situation of a typical street center located on the highway S.S. Tiburtina, where there is a ribbon-like commercial model polarized on specific aggregation areas (railway station, university). The second case study - the urban suburbs of Pescara - deals with the specific structure of the retail sector that hovers between settlement proposals and commercial desertification. The last case study is about the ethnic trade in Pescara and analyzes the relationship between space and ethnicity by means of a field research aimed at assessing the level of integration and, possibly, at observing areas of segregation and urban rifts.

\section{The commerce in the urban area of Pescara-Chieti: a multiple and progressive reading. Adaptations, peculiarities and vulnerabilities}

After the Second World War, the geographical proximity played a role of opposition between the two cities

\footnotetext{
2 This key has been the subject of critical analysis conducted by the PRIN Abruzzo working group. The conclusion to which reference should be made for specific in-depth analysis can be found in Fuschi,
} Ferrari 2019. 
of Pescara and Chieti, when the strong demographic and functional growth of Pescara (mainly due to internal migratory flows from mountain areas attracted by the increasing opportunities in the city) began to overshadow Chieti, where the effects of the economic boom were limited, notwithstanding its role as the industrial pivot for the Val Pescara area as well as the capital of a particularly vast and mountainous province.

During the 1970's and the 1980's Pescara (the only city in Abruzzo with a population of over one hundred thousand inhabitants) developed a first and second process of belt suburbanization (Fuschi 2001), in accordance with the typical dynamics of urban model, with settlement, industrial redistribution and tertiary centralization.

The suburbanization process of Pescara, thanks to the administrative and physical features ${ }^{3}$ of the area, affected other towns of the province of Chieti such as Francavilla al Mare and San Giovanni Teatino ${ }^{4}$. In this way the suburbanization process created a continuous and urbanized system; it also produced a link between the two cities, supported by suitable roadways and by the trade sector which represented a powerful way to create territorial convergence and cohesion.

Here the season of shopping centers has found a powerful demand basin, which has defined a dense urban area (Fig. 1$)^{5}$ whose vitality has ended up producing a process of emptying or, at least, of marginalizing proximity urban trade.

More specifically, Chieti (Ferrari 2019) dissipated the process of commercial accumulation because of the crisis in the secondary sector, the contraction of the public sector (offices and barracks), and an increased

\footnotetext{
${ }^{3}$ The city of Pescara borders the province of Chieti to the south and west.

${ }^{4}$ Francavilla al Mare, historically the favourite seaside resort for the city of Chieti, borders Pescara and San Giovanni Teatino to the north, and represents a connection between the two chief towns. Initially, Francavilla al Mare and San Giovanni Teatino have gradually absorbed the suburbanization process of Pescara. Later they have absorbed the functional suburbanization process too.

${ }^{5}$ This structure has begun in the 1990's supported by the first instances for the opening of shopping malls on regional and provincial scale. The first has been Mall (currently renamed Borgo d'Abruzzo) in Villanova di Cepagatti, followed by Auchan and Ipercoop in the municipal area of San Giovanni Teatino and Iper Pescara Nord in Città Sant'Angelo (towns of the first urban belt of Pescara, with San Giovanni Teatino belonging to the Chieti province). These shopping malls have been followed by several others (Centro Universo in Silvi Marina, Iper in Ortona, Megalò in Chieti Scalo and the Outlet Village in Città Sant'Angelo), giving reason for a high density value $\left(70.26 \mathrm{~m}^{2} / 1000\right.$ inhab.) which, since the beginning, has placed Abruzzo at the top of the southern regions and in the seventh place on the national scale (a higher value than the national average, $65.38 \mathrm{~m}^{2} / 1000$ inhab., and than the Mezzogiorno, 46.02 $\mathrm{m}^{2} / 1000$ inhab.) (our elaboration based on MISE data, 2017).
}

situation of downsizing and ageing population. This contraction was due to its limitations, lying in the poor accessibility and the geomorphological vulnerability, which sharpened the gap with the valley part of the settlement (Chieti Scalo). The contraction in commercial activities was undeniable, as well as significant: regarding the food sector from 1961 to 2016 there was a decrease from 571 employees and 336 activities to 223 employees and 117 activities, according to ISTAT data. While the retail located in the historical center underwent a progressive reduction of activities, in Chieti Scalo there was an increase in the trade sector due to the better accessibility, which acted as a glue and added value to its development. It was supported, in turn, by factors such as a greater concentration of young people and the larger size of the families than in the historical center, as well as the presence of a university campus. Actually the city is still struggling to find ways to bridge this gap (despite the approval in 2019 of a Municipal Business Plan that has not been applied yet), although its considerable artistic and cultural heritage - which has remained on the sidelines of the tourist offer for too long - could represent a driving force for improving the historic center following new trade and consumption patterns, in a context where a rethinking of the urban plan, in its unitary function, is still necessary.

In the second half of 1980's (Fuschi, Scorrano 2019), after gaining a historically leading position in the trade sector, Pescara coped with the crisis of the urban retail caused by the prominence of suburban shopping centers. Observing the ISTAT data, grocery stores decreased by $35 \%$ in the decade $1981-1991$ and by $16 \%$ in the following one, alongside the decline of the shops $(-11 \%$ in the decade 1981-1991 and -16\% in the decade 1991-2001). The city reacted to this scenario with a mixed public/ private commercial plan. After a long preparatory phase, it led to the establishment of the first Centro Commerciale Naturale (i.e. CCN, Natural Shopping Center) which involves the central streets of the city and whose aim is to enhance tourist, cultural and social sectors. At the same time, Pescara completed its transformation by gradually and partially replacing traditional trade activities with restaurants, making food a specific landmark associated with new habits of purchase and use of space. In doing so, foodscape ended up typifying the old town, located around the Bourbon fortress, and the CCN streets, with a significant growth in the sector over the last ten years. There were favorable responses able to fuel processes of urban rehabilitation, to support the tourist offer and to add new values and power of aggregation to the urban space. At the same time, it is also important to notice the limits of a sectorial plan which is poorly 


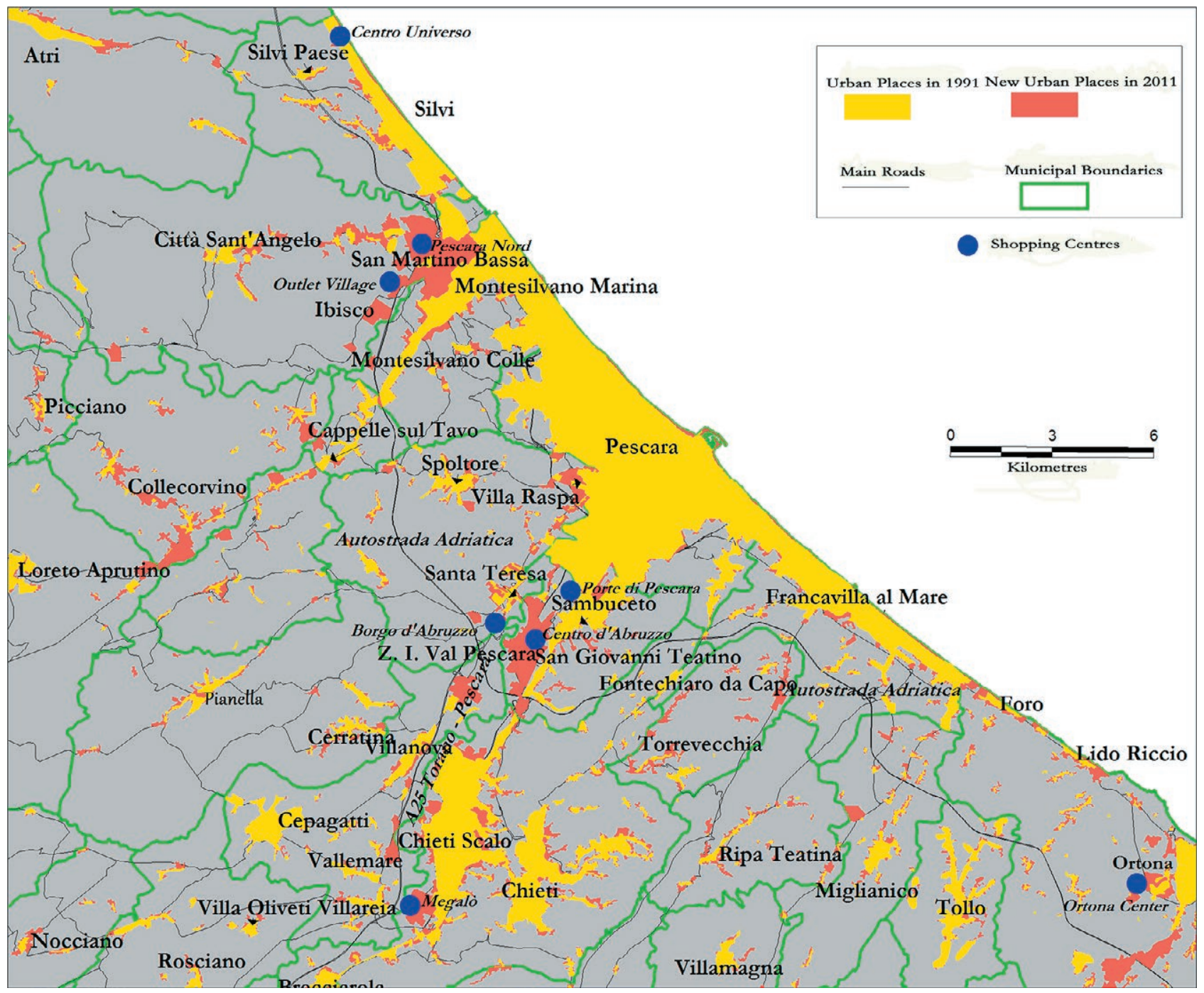

Figure 1. Location of Shopping Centers in the urban area of Pescara-Chieti. Source: elaborated by Fabrizio Ferrari.

integrated within a wider urban planning, and partial if compared to the dynamics of the interstitial and peripheral areas.

\section{The development of trade in a transit area in Chieti Scalo}

Chieti Scalo, as its own toponym reveals, is the valley part of the historical hilly core of Chieti. The term Scalo, in fact, refers to the railway line which has exploited the flat part of the site and around which has been built the first nucleus of the lower city. This case study, therefore, concerns a peculiar area of Chieti which, also from a supra-municipal perspective, is quite extended and relevant for trade and transportation. This area has developed a high agglomeration of heterogeneous commercial activities whose main localization factor is the accessibility. The observed area is represented by the urban section of S.S. 5 Tiburtina, the ancient junction between Rome and Pescara, fundamental for the Chieti transport system and for the connections between the Upper and the Lower Val Pescara (Fig. 2). Because of its importance, in 1975 the local authorities built the Asse Attrezzato (RA12) in order to solve congestion problems in the urban section, and to quickly connect Chieti with Pescara and the A25 with A14 motorways, avoiding the city center. The heavy traffic has improved the localization of commercial activities thanks to good accessibility and easy parking and, at the same time, has 
been a deterrent to the development of a certain sense of place, in which users can enjoy walking and shopping. The stretch of Tiburtina within the municipality of Chieti is divided in four segments, the central ones of which will be analyzed: Viale Abruzzo and Viale B. Croce. Regarding the urban landscape, in these streets there are a lot of one or two-storey houses, with the ground floors often dedicated to small businesses and the second floor often unused and in lousy conditions. Next to these edifices, there are other buildings with numerous floors, which were built for housing needs during the urban expansion of Chieti until 1990s, now mostly rented to university students. The fragmentation in small shops has determined two simultaneous phases. The first one is a phase of "release" (Dolega, Celińska-Janowicz 2015) of many activities, especially some of the traditional and historical ones that in many cases have not been affected by a generational renewal. The second phase is represented by an increase in non-commercial activities, that has determined the diversification of the offer but, on the other hand, it has induced negative effects on the dispositions of potential consumers, occupying "dead" spaces of shopping and dispersing commercial activities in ever larger spaces (Reimers, Clulow 2004).

On Viale Croce the commercial activities are organized into three segments: from the station to the intersection with Via Pietrocola and Via Penne there is a stretch with the oldest buildings in which there are small shops, especially clothing stores; up to the intersection in Via Campobasso, there is the most modern stretch with heterogeneous activities including restaurants; along the last section there are tenement buildings and medium-sized commercial areas with medium-low range products.

About the configuration of Viale Abruzzo, the first part up to Via Mattei is like the first segment of Viale Croce, but the buildings are newer and the shops more heterogeneous. In the second section, up to the intersection with Via Vibrata, there is a concentration of commercial and recent areas used as food supermarkets, household goods, linen and clothing garments stores. Regarding the last stretch of this street ${ }_{2}$ there is a low intensity of commercial activities and semi-rural residences; in this area we can also detect a large urban void around the Municipal Stadium.

Thanks to a field research carried out jointly with an analysis on the Chambers of Commerce, it is possible to notice some characteristics of the road sections outlined: on Viale Abruzzo out of 337 locations 175 are for civic use (buildings, gates, etc.), 24 are empty (most of them are for sale or for rent), 58 are dedicated to activities that are not strictly commercial (real estate

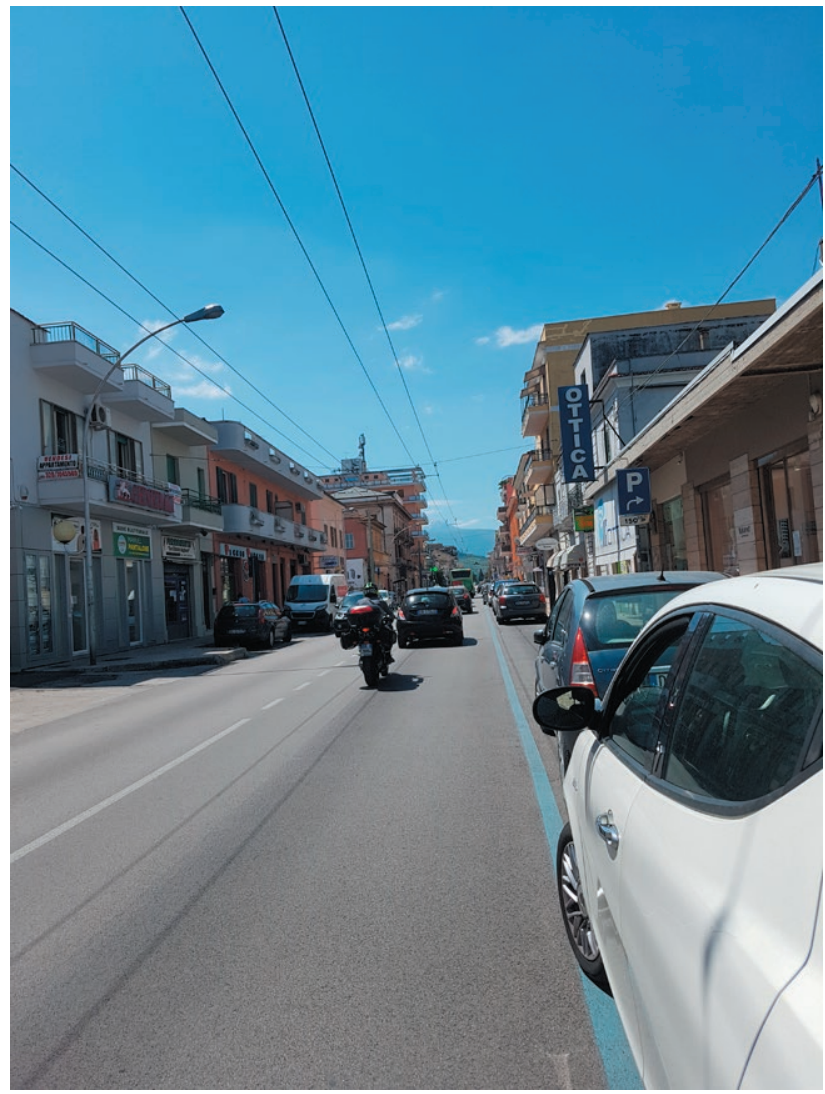

Figure 2. Chieti Scalo: a typical ribbon-like commercial model. Source: photo by Marina Fuschi.

agencies, hairdressers, car repair activities), 80 are dedicated to commerce and consume. Among these, 17 refer to clothing stores located in the initial part of the street and inside the small shopping center. It is important to notice that in this section there is a fairly large number of shops despite this area is near to the shopping mall Megalò where there are a lot of clothing stores. There are also 11 restaurants and 5 cafés, built up recently, and specialized in fast food and take-away (emphasizing the role of the street more as a transit space than as a resting place). The study on Viale Croce has demonstrated that, out of 402 locations, 198 are for civic uses, 31 are empty, 71 are for other uses (also in this case real estate agencies, hairdressers, but also some residual wholesale activities) and 102 are commercial activities. Of the latter, 13 are clothing activities, located in the first section in continuity with the stores of Viale Abruzzo, while 18 are related to the restaurant business which are recently enlivening the street's nightlife. In addition, there are support activities and others such as hardware stores and jewelry stores. 
At a glance, the lack of attractions, including architectural ones, gives an image of a street where there are mostly service activities particularly relevant to the local community, but which are only worth the time of a brief stop. Most of restaurants and cafés, which are increasing in recent years, do not have external dehors, even if they have had an increase in clientele, especially the students, who tend to decrease during the summer. However, it is possible to outline a nightscape initial phase (Chatterton, Hollands 2003), especially on Viale Croce, but it is necessary to requalify these streets, which should take a central role within the urban fabric of Chieti Scalo. In February 2020, a vote was held on a motion to name one of the streets of Chieti Scalo as Corso, formally recognizing the need of a central place in the lower part of the city. At the same time, it also necessary to implement concrete actions, including rehabilitation and gentrification policies (Bridge, Dowling 2001), and to establish spaces for social and commercial life. In this sense, it is important to point out some annual initiatives such as the Notte Bianca dello Scalo; during this event, which lasts only a few nights, the interruption of large road traffic occurs in a perimeter around the station, an element of strength and at the same time of weakness, involving also the initial section of the Via Colonnetta and some contiguous crossroads. A hypothesis of pedestrian area, however, is not practicable for long time, because of the pivotal role of these streets even in the metropolitan area; therefore, it will be necessary to study new projects to increase the attractiveness of this area (Teller, Reutterer 2008). Some factors such as the potential degree of urban interaction and accessibility, the number of sociable activities such as catering ones, can transform this area into a place of exchange rather than a place of competition against various local actors, for instance the nearby Megalo shopping mall or other services as the University, creating a hybrid and fluid area, capable of transforming itself and potentially attracting new visitors and users. (Kärrholm et al. 2014). On the other hand, the high rate of empty or abandoned facilities must induce incentives to occupy spaces in order to a give a global image of an alive area (Dolega, Lord 2020), considering that public incentives for localization, like the reduction in local taxes, have been successful in other districts of Chieti. These dynamics are part of a larger and systemic vision through which the city must reconnect the relationship between the upper part and the lower part, through planning processes favored by the recent approval of the municipal commercial planning. This is a significant perspective to counterbalance the actual Scalo role, as connection area between neighboring municipalities, therefore tending to marginalize the hilly historic center.

\section{The role of commerce/consumption in the urban suburbs of Pescara}

The establishment of the city of Pescara is the result of the aggregation of some municipalities whose centralizing element could be identified in the parishes (Madonna del Fuoco, Madonna dei Sette Dolori) surrounded by a rural neighborhood. This process has induced a functional and social differentiation of urban spaces through the progressive evolution of the urbanization process and the consequent building growth of the city. According to the typology of the social and building fabric, the area (even if it is an urban space of about thirty-four square kilometers) allows to outline at least three different suburbs. During the immediate post-war period in the central area ${ }^{6}$ the urban development took place in compliance with a social balance in which public housing coexisted with conventional and luxury residential buildings. About twenty years later in the northern suburbs of Pescara (Zanni) and along the southern inner section of Pescara river (Villa del Fuoco and Rancitelli; Fontanelle and San Donato) there was a significant concentration of houses built in the framework of the public residential building planning (Cavuta, Ferrari 2019); over the years this situation led to a gradual expulsion of the middle-class, with related damages in terms of economic depreciation of real estate and commercial activities, which in turn caused a spiral of degradation, fertile ground for the underworld ${ }^{7}$. The building development in Pescara - partly planned, partly subject to the free action of real estate market - produced a spatial and social fragmentation (Scorrano 2011); in this situation, the places of commerce, intended as spaces for social aggregation and free time, also reproduced and reinforced the spatial rifts. Three different types of urban suburbs - each with peculiar commercial features - came into conflict with the central city (which identified a Natural Shopping Center in Piazza della Rinascita, also known as Piazza Salotto) and the neighboring commercial galleries.

The first one, the Città Giardino, characterized by a high-quality residential demand, was planned during the fascist period along the coastal strip to the South of Pescara (bordering the municipality of Francavilla al Mare) and also extends along the hilly section of San Silvestro.

The second type of urban suburb, characterized by social housing, is represented by degraded social and

\footnotetext{
${ }^{6}$ The expression "central" refers to the northern part of the Pescara river corresponding to the central section of the historic municipality of Castellammare Adriatico (Fuschi, Scorrano 2019).

7 The residential complex known as Ferro di Cavallo in the Rancitelli district can be considered as an example.
} 
economic areas (Zanni; Villa del Fuoco and Rancitelli; Fontanelle and San Donato).

The third one is Pescara dei Colli Madonna (divided into Santuario and Colli Nord districts), so named, according to the writer, because of its identity mark represented by the eighteenth-century Basilica della Madonna dei Sette Dolori. This urban suburb can be considered almost as a second town thanks to its urban functions (also including a branch of the Municipal Offices). The various urban and social aspects outlined lead to a series of questions about the role currently played by the retail sector. Furthermore, current trends involving commercial and leisure services, with aggregative purposes, could represent a tool to recover the degraded suburbs (Howard 2007). But are there central commercial areas in the above outlined suburbs, and what role do they play for the residents? Starting from the northern suburbs of Pescara, the Via Nazionale Adriatica Nord represents the main road and commercial artery which, by cutting the coastal strip into two portions, constitutes a boundary line between the area of urban decay to the west and the area of the building recovery and of the villas revalued by the opening of the Strada Parco - a cycle and pedestrian street originating from the displacement of the urban section of the railway line - to the east.

Along the Via Nazionale Adriatica, near Zanni district, the opening of the urban shopping mall Delfino has represented a meeting and stopping point for the elderly even if there are only 16 shops there, housed inside a rather small area. The neglected courtyard of the social housing and the sense of insecurity are counterbalanced by the possibility to enjoy a protected place like Delfino, that performs a social more than a commercial function for the economically weak population of the area. In the studied area there are three food discount stores, two of which are located on the Via Nazionale Adriatica: coming from the south, the first one is a few hundred meters before Zanni, in a connection section with the hilly zone; the second one is in the center of Zanni; the third one, recently opened, is at the end of the social housing area. Therefore, there is an important commercial area near Zanni district, which, thanks to the presence of supermarkets, food discounts and specialized large-scale distribution, also attracts residents from the hilly area and the coastal strip north of the central town. The movement of consumers heading towards the area tends to reduce the segregation effect that characterizes the popular district; in addition, the existence of a shopping center, which already performs an aggregative function, implies an enhancement and a diversification in the use of commercial spaces that can also be used for cultural events. In the inner peripheral area at the south of the Pescara river (Villa del Fuoco and Rancitelli), - more affected by degradation than the northern suburbs - large-scale commercial activities are located on the edge of the area, leaving the inner suburb served by scarcely profitable retail stores. Thus, Villa del Fuoco, Rancitelli, Fontanelle and San Donato districts represent an economic and social periphery just crossed to reach the places of large-scale distribution and the shopping centers of San Giovanni Teatino; that is due to a lack of private aggregative spaces with commercial and recreational functions and to the poor conditions of public infrastructures.

Contrasting commercial desertification, enhancing commercial and recreational spaces structured as shopping centers, privatizing public spaces to guarantee safety for traders and consumers are necessities and strategies to fight the social and economic hardship of the popular suburbs. On the other hand, in the residential suburbs of the Città Giardino, thanks to the propensity to mobility of the residents, places of aggregation are not necessary as demonstrated by the downgrading of a shopping mall into a supermarket.

As already pointed out, in the northern hilly area, the intense building development process (started in the 1990's) led to the creation of an urban continuum consisting of terraced houses and buildings. Around Largo Madonna dei Sette Dolori, a suburb with marked rural features and a small center with tertiary functions was replaced by social housing, and the purchase needs of the residents have been for a long time satisfied by neighboring sales points located along the historical urban section linked to the coastal strip.

However, the urban expansion led to the planning of a second commercial hub at the beginning of Via di Sotto, where some large-scale retail businesses and services for citizens - such as gym, laundry, café, Carabinieri barracks and a municipal offices branch - have settled. This area is served by a large parking lot and it is also facilitated by its position along one of the main road arteries.

Furthermore, the opening of the Arca, a shopping mall with leisure facilities in the neighboring municipality of Spoltore, which is also located in an area historically linked to the Pescara dei Colli Madonna, represents a meeting and cultural place and a space where community identity elements are consolidated.

Now, Pescara, although requalified in its central spaces, must recover its peripheries degraded by social and economic problems. This regeneration has to concern the renewal of the building structure (e.g. the proposal to break down the Ferro di Cavallo), but it also has to act on the social fabric, operating on the spaces of aggregation and on everyday life, on the commercial 
and craft neighborhood activities, and especially on the sense of belonging to a territory. In a renewed context of social security, all these elements can find a strength in structures capable of mixing the commercial offer with leisure activities.

\section{Ethnic trade in Pescara: an enclave in the central urban fabric}

In the glocalized context of large urban areas widely crossed by global flows, talking about trade without analyzing the type of ethnic supply would give a distorted view of the local economic reality. Ethnic trade is characterized by a double interesting aspect; if on the one hand it recalls the characteristics of what we could define premodern commercial space, characterized by the destructuring of sale activities, the spaces informality, "the interpenetration between street life and shops' commercial activities"; on the other hand it follows the postmodern typical "space-time compression", as well as the proximity to stations, ports and other infrastructural nodes, enhancing flexible urban fabrics. (Lanzani 2003). In one of the areas that are considered central there is an enclave, a sort of small city within the city and an agglomeration of different ethnic groups, which is the case study of this analysis. This area includes one of the main urban arteries, Corso Vittorio Emanuele II, connected with some perpendicular streets and with the coastal strip ${ }^{8}$. The present field research aims at detecting the number and the trend of ethnic trade in one of the most significant areas of the Adriatic city, not so much from the quantitative point of view of the phenomenon - which is widespread in Pescara - but rather for its centrality in the urban fabric. This perspective is very important, being this area exactly halfway between the railway station and the streets which represent the fulcrum of the city commerce, including the luxury one, and the promenade 9 . Indeed, the ethnic enclave has occupied the central spaces left empty by the residents - both in housing and commercial terms - producing an unsafe commercial landscape, in some cases quite degraded, characterized by a general atmosphere of insecurity with shops and shop windows uncaredfor. In this context of closure and distrust, the various ethnic groups tend to produce forms of mutual support, while, on other side, there is little openness to integra-

\footnotetext{
${ }^{8}$ These streets are Via Piave, Via Mazzini, Via Quarto dei Mille, which, together with Via de Amicis, circumscribe Piazza Santa Caterina da Sie$n a$, delimiting the study area with Piazza dei Martiri Pennesi.

${ }^{9}$ Starting from 2014 there has been the establishment of the Natural Shopping Center along these streets.
}

tion by the local population. Through the field survey it has been possible to detail the quantity and the type of ethnic shops currently present, noting a high concentration of activities although they are in a really small area: out of the total 29 stores, about $31 \%$ is represented by grocery stores (mainly Chinese and African, and then Romanian), followed by a $21 \%$ of ethnic restaurants, and by around $14 \%$ of phone, technology and repair shops (mainly Chinese and Indian). Greengrocers, costume jewelry shops and international couriers - who deal with the movement of goods and people between Italy and Romania - account for about a 7\% each. Lastly, general store, tailoring, clothing and internet point are all present with a single unit (each accounting for 3.4\%).

Comparing the data collected through the field research with those provided by the Chambers of Commerce (February 2019), a very interesting historical profile comes out, as about $55 \%$ of the commercial spaces currently run as ethnic have hosted over the years at least another ethnic shop, which indicates a sort of loyalty towards the place by foreign communities.

Since the 1970's, in fact, the ethnic phenomenon begun to develop in Pescara, particularly with African communities in the form of itinerant trade, which was also due to the seaside that characterizes the city; only since the 1980s ethnic groups have taken root downright in this area, becoming part of the local economy and have witnessed the arrival of other groups such as the Chinese, the Iranians and others from Eastern Europe. In this context it's important to highlight "the relationship between space and ethnicity", as the foreign population settled in spaces left empty by the local population, which moved to peripheral hilly and flat areas after the building development of the late 1980s (Fuschi, Scorrano 2009). This phenomenon has generated a process of urban substitution, limiting the areas of abandonment, in some cases reaching a sort of new enhancement of the urban space (Lanzani 2003). Today we are still far from talking about a real socio-cultural integration. Indeed, recent analyzes have shown that the differential incorporation theory has much more evidence than the spatial assimilation theory, so that the settlement and the integration of foreign communities do not depend exclusively on the socio-economic aspects relating to the origin, but rather on the reception capacity and the openness of the local population (Cristaldi 2012). Exemplifying, in this sense, is another situation related to ethnic Senegalese peddlers, who have occupied for years, mostly illegally, the area in front of the station, with rows of stalls used during the day for commercial activity and transformed into bedding at night, with a result far from satisfactory. About four years ago this place has been 


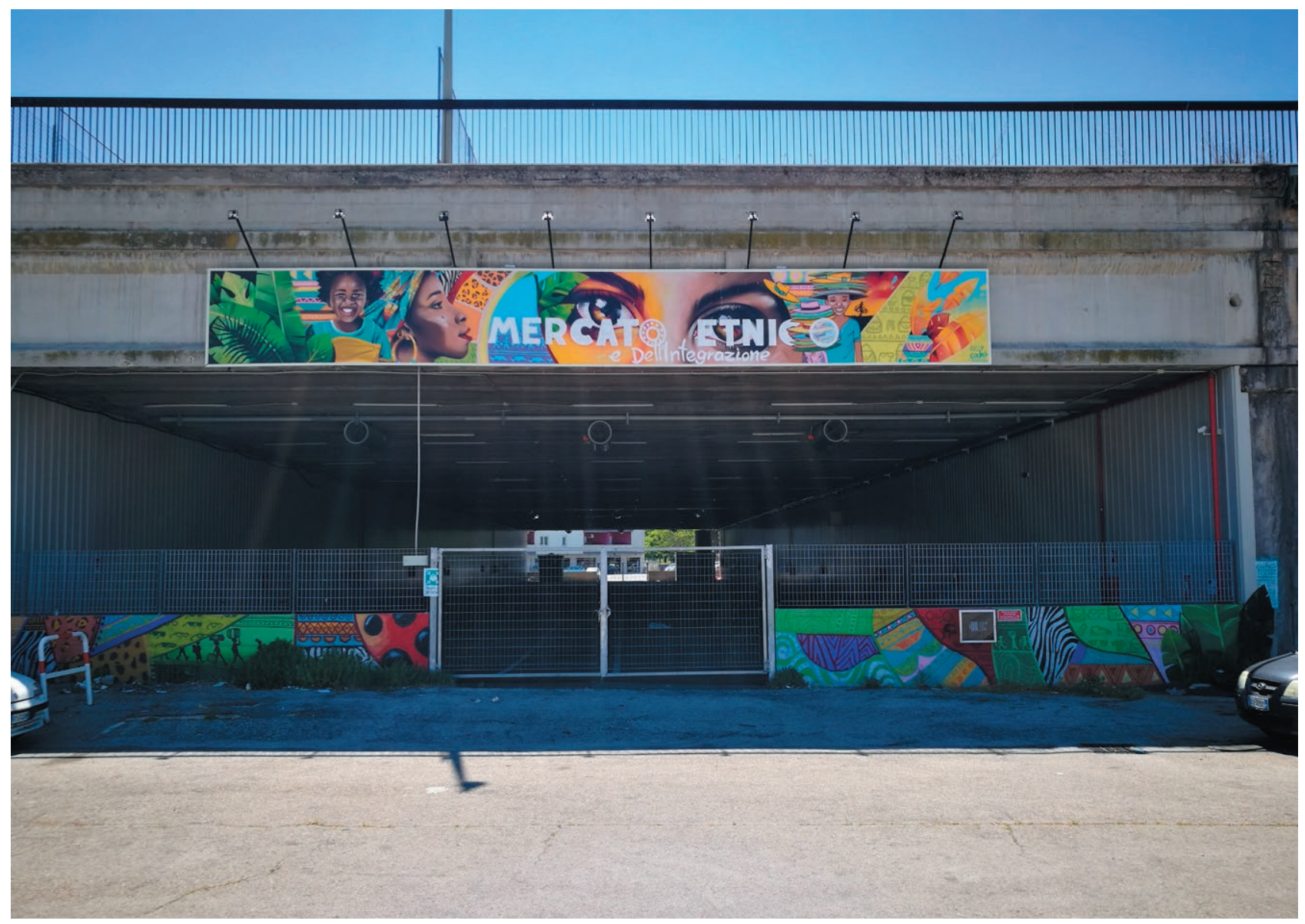

Figure 3. Area intended for ethnic market in the railway underpass in Pescara. Source: photo by Silvia Iacuone.

dismantled with the promise of creating a space where those traders could have worked legally and safely; a promise that seemed could be fulfilled last year with the ethnic market, located in a dedicated space in the railway underpass of the central station (Fig. 3).

This project raised controversies from several parties such as Confcommercio, the political opposition and the foreigners themselves, who considered this idea as discriminatory and ghettoizing. Also this case, as indeed the widest phenomenon of emerging degradation in the analyzed area, prefigures an enclave and confirms the idea of a structurally rifted and poorly integrated city. Pescara would need political strategies aimed at building a systemic vision of the city able to support a real and combined integration of this new aspect of the economy (Panzarella 2010). These issues represent a mirror of the concept of glocality that characterizes today's society, favoring interrelations that are necessary both for the economic development and for the connection of the social fabric in order to achieve a cultural expansion.

\section{Conclusions}

The case studies analyzed in this paper have tried to look beyond the contrast, widely debated in the literature, between the favorable period of the large commercial format and the trade crisis in the central and historical areas of the city. This means to overcome a homologating description of the city, by adopting a multiple and complex view which moves from suburbs, interstitial areas and peculiar spaces, in order to better narrate urban identity. This type of study offers a privileged position from which to foster a balanced and sustainable reorganization of the city. Indeed, this seems to be the most urgent aspect highlighted by the studies about Chieti Scalo and the suburbs and the ethnic trade of Pescara. The retail sector, in its private dimension but mainly in public planning, does not seem to be able to reconfigure the urban shape in its unitary dimension, thus confirming internal rifts, large residual spaces and even segregation areas. It is necessary to start to follow a cooperative logic 
aimed at promoting "functional integration processes of different offers and complementarity formats with other types of functions located in a large territorial system" (Brunetta 2012, 75). In this way, on the basis of proven mutual benefits for the urban system, it is possible to produce virtuous effects of reactivation and/or consolidation of urban commerce in peripheral and/or peculiar areas.

\section{References}

Bottini, F. (2005). I nuovi territori del commercio. Società locale, grande distribuzione, urbanistica. Firenze, Alinea Editrice.

Bridge, G., Dowling, R. (2001). Microgeographies of retailing and gentrification. Australian Geographer, 32 (1), 93-107.

Brunetta, G. (2012). Non solo commercio. Da politiche di settore alla sperimentazione dei distretti territoriali del commercio. Archivio di studi urbani e regionali, 103, 72-80.

Bullado, E., Buzzetti, L. (Eds.). (2001). La rivoluzione terziaria. Riorganizzazione geografica del Commercio. Trento, Artimedia.

Carreras i Verdaguer, C., D’Alessandro, L. (2017). Un repertorio bibliografico su commercio, consumo e città. In Viganoni L. (Ed.). Commercio, consumo e città, Quaderno di lavoro. Milano, Angeli, 27-69.

Cavuta, G., Ferrari, F. (2019). Disagio sociale urbano e attività economiche: coesistenze e divergenze. Il caso di Pescara. Semestrale di Studi e Ricerche di Geografia, 31 (2), 23-39.

Chatterton, P., Hollands, R. (2003). Urban Nightscapes. London, Routledge.

Cirelli, C. (Ed.). (2007). Gli spazi del commercio nei processi di trasformazione urbana. Bologna, Pàtron.

Cirelli, C. (Ed.). (2009). Città e commercio. Bologna, Pàtron.

Cirelli, C. (Ed.). (2016). Le nuove geografie del consumo tra crisi e resilienza. Geotema, 51.

Clerici, M.A., Faravelli, M.L. (2006). Connettere diversità: il commercio nel recupero di unantica via in Val Vigezzo. Territorio, 39, 268-273.

Cristaldi, F. (2012). Immigrazione e territorio: la segregazione residenziale nelle aree metropolitane. Geotema, 43-44-45, 17-28.
D’Alessandro, L. (Ed.). (2015). City, Retail and Consumption. Napoli, Università degli Studi di Napoli "L'Orientale".

D’Alessandro, L., Viganoni, L. (2013). Consumo di lusso e cambiamento urbano. Le Main Streets di Napoli. Bollettino della Società Geografica Italiana, VI, 401-422.

Dolega, L., Celińska-Janowicz, D. (2015). Retail resilience: a theoretical framework for understanding town center dynamics. Studia Regionalne i Lokalne, 2 (60), 8-31.

Dolega, L., Lord, A. (2020). Exploring the geography of retail success and decline: A case study of the Liverpool City Region. Cities, 96. DOI: https://doi.org/10.1016/j. cities.2019.102456

Ferrari, F. (2019). Crisi del commercio tradizionale e transizione verso nuovi modelli di consumo in una città di provincia: il caso di Chieti. In Fuschi M., Ferrari F. (Eds.). Commercio e consumo nelle città d'Abruzzo. Casi studio. Milano, Angeli, 143-196.

Fuschi M., Scorrano S. (2009). La trasformazione del paesaggio urbano pescarese: tra preesistenze, nuove centralità $\mathrm{e}$ dinamiche sociali. In Sommella, R. (Ed.). Le città del mezzogiorno. Politiche, dinamiche, attori. Milano, Angeli, 175-189.

Fuschi, M. (2001). Città: ciclo di vita e modernizzazione. Larea urbana pescarese. In Lago, L., Favretto, A. (Eds.). La geografia delle sfide e dei cambiamenti: Atti del XXVII Congresso geografico italiano. Bologna, Pàtron, 415-424.

Fuschi, M. (2006). Il sistema urbano nella regione del Medio Adriatico. Una lettura di sintesi attraverso l'Indice di Urbanità. In Fuschi, M. (Ed.). Per una regione medioadriatica. Città, territorio, economia. Milano, Angeli, 232-239.

Fuschi, M., Ferrari F. (Eds.). (2019). Commercio e consumo nelle città d'Abruzzo. Casi studio. Milano, Angeli.

Fuschi, M., Scorrano S. (2019). Pescara: la scommessa del commercio. Quale idea di città? In Fuschi, M., Ferrari, F. (Eds.). Commercio e consumo nelle città d'Abruzzo. Casi studio. Milano, Angeli, 75-115.

Howard, E. (2007). New shopping centers: is leisure the answer? International Journal of Retail \& Distribution Management, 35 (8), 661-672.

Jackson P. (2002). Commercial Cultures: Transcending the Cultural and the Economic. Progress in Human Geography, 26 (1), 3-18.

Jackson, P., Thrift, N. (1995). Geographies of Consumption. In Miller, D. (Ed.). Acknowledging Consumption. A Review of New Studies. London \& New York, Routledge, 204-237. 
Kärrholm, M., Nylund, K., Prieto de la Fuente, P. (2014). Spatial resilience and urban planning: addressing the interdependence of urban retail areas. Cities, 36, 121-130.

Landini, P. (1976). Contributo all'individuazione di unità sub-regionali in Abruzzo, Notiziario Geografia Economica, n. 3-4, 34-54.

Landini, P. (1981). Caratteri geografici del terziario commerciale in Italia, Bollettino della Società Geografica Italiana, 11-46.

Landini, P., Massimi, G. (2010). Sismicità, insediamento, economia. Analisi geografica nelle aree del terremoto d'Abruzzo (2009). Bollettino della Società Geografica Italiana, XIII-III (2), 287-339.

Lanzani A., (2003). I paesaggi italiani. Milano, Meltemi.

Loda, M., Mancini, N. (2003). Imprenditoria extracomunitaria e commercio al dettaglio nei centri storici. Il quartiere di S. Lorenzo a Firenze. In Loda, M., Clemente, P. (Eds.). Migrare a Firenze. Firenze, Comune di Firenze, 125-150.

Massimi, G. (1989), La conurbazione pescarese. Un'introduzione geografica. In Di Blasi A. (Ed.). L'Italia che cambia. Il contributo della geografia. Catania, Atti del XXV Congresso Geografico Italiano, Vol. IV, 153-168.

MISE (2017). Rapporto sul sistema distributivo. Analisi strutturale del commercio italiano. Roma.

Panzarella, A. (2010). Quali strategie per trasformare un'immagine repulsiva in attrattiva? Il commercio etnico nel centro storico di Palermo. In Ingallina, P. (Ed.). Nuovi scenari per l'attrattività delle città e dei territori. Dibattiti, progetti e strategie in contesti metropolitani mondiali. Milano, Angeli, 209-218.

Reimers, V., Clulow, V. (2004), Retail concentration: a comparison of spatial convenience in shopping strips and shopping centers. Journal of Retailing and Consumer Services, 11, 207-221.

Salvatori, F. (1993), Effetto città e territorio. La dimensione e le direttrici di propagazione della condizione urbana in Abruzzo. In Salvatori, F., Landini, P., (Eds.). Abruzzo. Economia e territorio nel Nord del Mezzogiorno. Pescara, Libreria dell'Università Editrice, 103-112.

Scorrano, S. (2011). Frammentazione sociale e frammentazione spaziale: un nuovo ordine per le città? In Di Blasi, A. (Ed.). Il futuro della geografia: Ambiente, culture, economia. Bologna, Patron, vol. I, 703-707.

Teller, C., Reutterer, T. (2008). The evolving concept of retail attractiveness: what makes retail agglomerations attractive when customers shop at them? Journal of Retailing and Consumer Services, 15(3), 127-143.

Wiedenhoft Murphy, W. (2017). Consumer Culture and Society. Thousand Oaks \& London, Sage.

Wrigley, N., Lowe, M. (1996). Retailing, Consumption and Capital: Towards the New Retail Geography. Harlow, Addison Wesley Longman.

Wrigley, N., Lowe, M. (2002). Reading Retail: a geographical perspective on retailing and consumption spaces. London, Arnold Publishers. 